\title{
Vasoconstriction of intrapulmonary arteries to P2-receptor nucleotides in normal and pulmonary hypertensive newborn piglets
}

\author{
${ }^{1}$ M.R. McMillan, ${ }^{2}$ G. Burnstock \& ${ }^{*, 1}$ S.G. Haworth \\ ${ }^{1}$ Institute of Child Health, 30 Guildford Street, London, WC1N 1EH and ${ }^{2}$ Autonomic Neuroscience Institute, Royal Free Hospital \\ Medical School, Rowland Hill Street, London NW3 2PF
}

1 The vasoconstrictor responses of isolated intrapulmonary arteries (IPA) to P2-receptor agonists was investigated during adaptation to extrauterine life in the normal piglet and the effect of pulmonary hypertension was studied following exposure of newborn animals to chronic hypobaric hypoxia $(51 \mathrm{kPa})$ for 3 days.

2 At resting tone, $\alpha, \beta$-methyleneATP $(\alpha, \beta$-meATP) (P2X-receptor agonist) contracted intrapulmonary arteries from adult, but not immature pigs, and repeated application desensitized the response.

3 Adenosine 5'-triphosphate (ATP) induced endothelium-independent relaxation at low concentrations at all ages, a variable contractile response to high concentrations developed by 3 days, becoming larger and consistent by 14 days of age.

4 Uridine 5'-triphosphate (UTP) evoked a contractile response in normal intrapulmonary arteries from foetal to adult life, the magnitude of the response increasing with age. Endothelial removal and pre-incubation with $\mathrm{N}^{\omega}$-nitro-L-arginine methyl ester (L-NAME) $(100 \mu \mathrm{M})$ increased the contractile response of adult vessels.

5 Pre-incubation with $\alpha, \beta$-meATP $(100 \mu \mathrm{M})$, increased the contractile response to UTP in both newborn and adult vessels. ATP-induced relaxations were reduced in newborn vessels but there was no effect on the responses of adult vessels.

6 Responses to UTP, ATP and $\alpha, \beta$-meATP of intrapulmonary arteries from newborn piglets exposed to chronic hypobaric hypoxia for 3 days were normal.

7 In summary, UTP elicited marked vasoconstriction of porcine IPA at all ages. UTP and ATP responses were consistent with activation of the $\mathrm{P}_{2} \mathrm{Y}_{4}$-receptor recently identified in vascular smooth muscle by others. $\alpha, \beta$-meATP induced a small vasoconstriction in the adult probably via the $\mathrm{P}_{2} \mathrm{X}_{1^{-}}$ receptor. Responses remained normal in neonatal pulmonary hypertension.

Keywords: Pyrimidine; purine; pulmonary artery; neonatal hypertension; vasoconstriction

Abbreviations: Ach, Acetylcholine; ANOVA, analysis of variance; ATP, adenosine 5'-triphosphate; IPA, intrapulmonary artery; $\mathrm{KCl}$, potassium chloride; L-NAME, $\mathrm{N}^{\mathrm{w}}$-nitro-L-arginine methyl ester; $\alpha, \beta$-meATP, $\alpha, \beta$-methylene adenosine $5^{\prime}$ triphosphate; PAP, pulmonary arterial pressure; PGF $_{2 \alpha}$, prostaglandin $\mathrm{F}_{2 \alpha}$; PPHN, persistent pulmonary hypertension of the newborn; PSS, physiological salt solution; UTP, uridine 5'-triphosphate

\section{Introduction}

The pulmonary vascular resistance is high in utero and remains elevated in persistent pulmonary hypertension of the newborn (PPHN), a clinical syndrome most commonly associated with hypoxic lung disease (Haworth, 1979; 1993). Whether or not nucleotides play a role in maintaining a high resistance in either of these circumstances is not known.

ATP can produce either relaxation or contraction depending upon the P2-receptor subtype(s) present in the tissue and the tone of the vessel investigated (Burnstock, 1997), suggesting that the pulmonary arterial response to ATP might change with age in normal pulmonary arteries as the vascular resistance falls after birth due to maturation of vascular reactivity and structure (Allen \& Haworth, 1998; Hall \& Haworth, 1987; Haworth et al., 1987; Levy et al., 1995; Liu et al., 1992). At low vascular tone, vasoconstriction to ATP is the dominant response, mediated by $\mathrm{P} 2 \mathrm{X}$-receptor(s), partly via the $\mathrm{P} 2 \mathrm{X}_{1}$ subtype on smooth muscle and partly by P2X subtypes which have not yet been clearly identified (Benham \& Tsien, 1987; Neely et al., 1991; 1996). Currently there are seven recognized $\mathrm{P} 2 \mathrm{X}$-receptors, including the non-selective ion pore $\mathrm{P} 2 \mathrm{X}_{7}$ (formerly P2Z) (Burnstock, 1997). Transcripts of receptor

*Author for correspondence.
mRNA for the P2X $\mathrm{X}_{1,2}$ and 4 -receptor sub-units have been colocalized by in situ hybridization in adult rat aortic and pulmonary arterial smooth muscle (Nori et al., 1998). The metabolically stable ATP analogue $\alpha, \beta$-meATP evoked a contractile response in the isolated guinea-pig taenia coli and then desensitized P2X-receptors, without significant vasodilator activity (Kasakov \& Burnstock, 1983; Kennedy \& Leff, 1995). ATP induces a contraction in isolated adult human and rat pulmonary artery and $\alpha, \beta$-meATP can block the response suggesting that these agonists act via a common receptor (Liu et al., 1989a,b). However, in the isolated perfused adult rat lung, vasoconstriction to ATP was only partially inhibited by $\alpha, \beta$-meATP (Rubino \& Burnstock, 1996). Pyrimidines (uridine nucleotides) are also known to evoke $\alpha, \beta$-meATP-insensitive vasoconstriction of some systemic and pulmonary vessels (Juul et al., 1993; Matsumoto et al., 1997; Ralevic \& Burnstock, 1991; 1998; Saiag et al., 1987; 1990); von Kugelgen \& Starke, 1990). They can be released from the vascular endothelium of rabbit thoracic aorta, and from platelets, suggesting physiological sources (Goetz et al., 1971; Saiag et al., 1995). Pyrimidineinduced vasoconstrictions reported for the adult rat small pulmonary artery and adult rabbit coronary artery were thought to be mediated by members of the G-protein coupled, P2Y-receptor family, which can activate phospholipase C 
through $\mathrm{G}_{\mathrm{q} 11}$ and subsequently stimulate a rise of intracellular calcium (Burnstock 1997; Nicholas et al., 1996; Hartley et al., 1998; Matsumoto et al., 1997). Recently, adult rat aorta smooth muscle has been shown to express $\mathrm{P} 2 \mathrm{Y}_{2,4}$, and 6 , subtypes, which are known to be activated by pyrimidines (Harper et al., 1998).

Persistent pulmonary hypertension of the newborn is a potentially fatal condition, which results in abnormal remodelling of the intrapulmonary arteries during the first few days of life (Allen \& Haworth, 1986; Haworth, 1979; 1993). The marked hypertrophy of the IPA smooth muscle cells has been taken to indicate an increase in contractile response to different stimuli, including hypoxia. The role of purines and pyrimidines in this condition is unknown. In an experimental study using the perfused adult rat lung, the vasoconstrictor response to acute alveolar hypoxia could not be attributed to up-regulation of $\alpha, \beta$-methylene-sensitive P2Xreceptors (McCormack et al., 1989).

In the present study, the response of normal, isolated porcine IPA to cumulative doses of ATP, $\alpha, \beta$-meATP and UTP was investigated from foetal to adult life. We also studied $\mathrm{P} 2 \mathrm{X}$-receptor desensitization by $\alpha, \beta$-meATP on the response to ATP and UTP. The effect of neonatal pulmonary hypertension was determined in the IPA of newborn piglets which had been exposed to chronic hypobaric hypoxia for 3 days (Tulloh et al., 1997).

\section{Materials}

\section{Preparation of tissue}

Piglets were produced by pregnant Large White sows at term. Animals were killed by an intraperitoneal injection of sodium pentobarbitone (Expiral $100 \mathrm{mg} \mathrm{kg}^{-1}$ ) when $5 \mathrm{~min}-$ $3 \mathrm{~h}$ old and at 3 and 14 days of age. In addition, heart-lung blocks from foetal (5 days pre-term), 3, 14 day and adult animals (9-months-old) were delivered from a recognized tissue supplier in cold physiological salt solution. Normal newborn piglets were exposed to chronic hypobaric hypoxia $(51 \mathrm{kPa})$ for a period of 3 days in a hypobaric chamber. Piglets exposed to hypoxia were regularly provided with fresh water and piglet feed (Sow Milk Equivalent, SCA Nutrition Ltd., U.K.) ad libitum, in addition to tube feeding as required. The chamber was illuminated and maintained at a temperature of $25^{\circ} \mathrm{C}$ (Tulloh et al., 1997). The treatment of all animals followed the guidelines set down in the British Home Office regulations and in the 'Principles of Laboratory Animal Care' (National Institutes of Health, publication number 80/23, revised 1978).

\section{Organ bath experiments}

The main intrapulmonary conduit artery (IPA) was dissected from the middle third region of a lower lobe, placed in calcium containing physiological salt solution (PSS: $\mathrm{NaCl} 119 ; \mathrm{KCl}$ 4.7; $\mathrm{NaHCO}_{3} 25 ; \mathrm{MgSO}_{4}$ 1.2; $\mathrm{KHPO}_{4}$ 1.2, $\mathrm{CaCl}_{2}$ 2.5, glucose $11 \mathrm{mM})$ and cleaned of lung parenchyma and connective tissue. The vessel was cut into rings $2-4 \mathrm{~mm}$ long, external diameter range of $1.5 \mathrm{~mm}$ (foetal) to $3.5 \mathrm{~mm}$ (adult). The endothelium was removed from selected rings by mechanical rubbing with a metal tool. Two horizontal tungsten wires (120 $\mu \mathrm{m}$ diameter) were inserted through the vessel lumen and then mounted for isometric force recording in $5 \mathrm{ml}$ organ baths. Isometric force data was recorded in a digital format using Chart software on a MacLab computer system. The rings were allowed to stabilize for at least $40 \mathrm{~min}$, during which time the PSS was replaced once and the tension gradually increased to $1000 \mathrm{mg}$, in vessels from all animals. Contraction to $30 \mathrm{~mm}$ potassium chloride $(\mathrm{KCl})$ established the presence of smooth muscle function in all preparations. In order to verity that the endothelium was intact or had been removed effectively, in animals aged 3 days or more acetylcholine (ACh) $(1-10 \mu \mathrm{M})$ was added in the presence of a stable contraction to $\mathrm{PGF}_{2 \alpha}(10$ or $30 \mu \mathrm{M})$, to detect endothelium-dependent relaxation (Liu et al., 1992). Conduit porcine IPA from younger or pulmonary hypertensive animals do not relax in response to ACh (Tulloh et al., 1997). A contractile response to a second bolus of $\mathrm{KCl}(30 \mathrm{~mm})$ was determined, against which responses could be evaluated (in combination with the tension remaining after $100 \mu \mathrm{M}$ papaverine). The $\mathrm{KCl}$ was then washed out, allowing the baseline to stabilize again. A cumulative-concentration response curve to either $\alpha, \beta$-meATP $(0.01-100 \mu \mathrm{M})$, ATP $(0.001-30 \mathrm{mM})$ or UTP $(0.001-30 \mathrm{mM})$ was then carried out in rings from normal animals, from foetal to adult life, and in rings from neonatal hypoxic animals.

In order to investigate the role of the endothelium in the response to UTP, IPAs with endothelium from adult pigs were pre-incubated with either L-NAME $(100 \mu \mathrm{M})$ or indomethacin $(10 \mu \mathrm{M})$, both inhibitors being added before carrying out a cumulative-concentration response study to UTP. The effect of $\mathrm{P} 2 \mathrm{X}$-receptor desensitization upon the responses was investigated in normal newborn and adult porcine IPAs. Twenty minutes after carrying out a cumulative dose-response study with $\alpha, \beta$-meATP, a $100 \mu \mathrm{M}$ bolus of $\alpha, \beta$-meATP was added to confirm a P2X-receptor block. Then in the continued presence of $\alpha, \beta$-meATP, a cumulative dose response study to either ATP or UTP was performed on the same vessel. Finally, in each experiment, a bolus of papaverine $(100 \mu \mathrm{M})$ was given in order to remove all remaining tone. The change in tension between the peak of the contractile response to $30 \mathrm{mM} \mathrm{KCl}$ and the relaxation to $100 \mu \mathrm{M}$ papaverine was taken as the measure of greatest contractile activity, as $100 \%$ against which the response to $\mathrm{P} 2$-agonists was assessed.

\section{Drugs}

The drugs were purchased from Sigma and dissolved in distilled water unless stated otherwise: acetylcholine (hydrochloride salt), adenosine 5'-triphosphate (di-sodium salt), indomethacin, L-NAME, papaverine (hydrochloride salt), prostaglandin $\mathrm{F}_{2 \alpha}$ (Sigma and Cayman Chemical Company (made up in absolute ethanol), uridine $5^{\prime}$-triphosphate (sodium salt), $\alpha, \beta$-methylene adenosine $5^{\prime}$-triphosphate (from RBI).

\section{Statistical analysis}

Excel (version 7a) and SPSS (version 6.1.3) PC were used to do the following data analysis. The effect of age on the contractile response to $30 \mathrm{~mm}$ potassium chloride (including the basal tone revealed by giving $100 \mu \mathrm{M}$ papaverine) was assessed using a one-way analysis of variance (ANOVA) with post-hoc Bonferroni testing. One-way ANOVA was used for each P2receptor agonist to determine the concentration at which the effect of age was greatest. Bonferroni post-hoc testing was used to identify between which age groups the responses seen at this concentration were significantly different. A two-sample Student $t$-test was used to test the following: the influence of the endothelium on responses; the effect of L-NAME and indomethacin on the response to UTP in the adult; the effect of $\mathrm{P} 2 \mathrm{X}$-receptor desensitization by pre-incubation with $\alpha, \beta$ - 
meATP on the response to ATP and UTP. The effect of exposure to chronic hypobaric hypoxia from birth for 3 days was compared to normal age-matched data using a two-sample Student $t$-test.

\section{Results}

\section{Responses of intrapulmonary arteries from normal pigs}

A contractile response to a bolus addition of potassium chloride $(\mathrm{KCl})$ was present at all ages and the increase in tension was similar in IPA from foetal life until 14 days of age (Figure 1), but was significantly greater in normal adult vessels $(P<0.05)$. Removing the endothelium did not change the response at any age.

In IPA from normal foetal, newborn and 3 day-old piglets, cumulative addition of ATP induced a concentrationdependent relaxation which was independent of the endothelium (Figure 2a). In addition, small transient contractions were evoked at similar high concentrations in the 3 day-old, but not in younger animals. By contrast, in normal 2 week-old and adult pigs ATP-induced only a small relaxation, with a greater contractile response at high concentrations. Thus, there was a significant reversal from a pre-dominantly relaxant response to a contractile one as age increased $(P<0.05)$.

In IPA from piglets of all ages, cumulative addition of UTP induced a contractile response in vessels with and without endothelium (Figure 2b). The response in rings without endothelium increased significantly with age and was significantly greater in the adult than in foetal animals $(P<0.05)$. In adult IPA the contractile response was significantly greater in rings without endothelium $(P<0.05)$. Representative traces of ATP- and UTP-cumulative concentration response curves in newborn and adult IPA are presented (Figure 3a,b,c,d).

Cumulative-addition of $\alpha, \beta$-meATP only induced a significant response in adult IPA, when a small transient contraction was evoked at $10 \mu \mathrm{M}$ (Figure 2c). Removing the endothelium had no significant effect on the response at any age. In the normal adult porcine IPA the rank order of vasoconstrictor activity was $\mathrm{UTP}>\mathrm{ATP}>\alpha, \beta$-meATP.

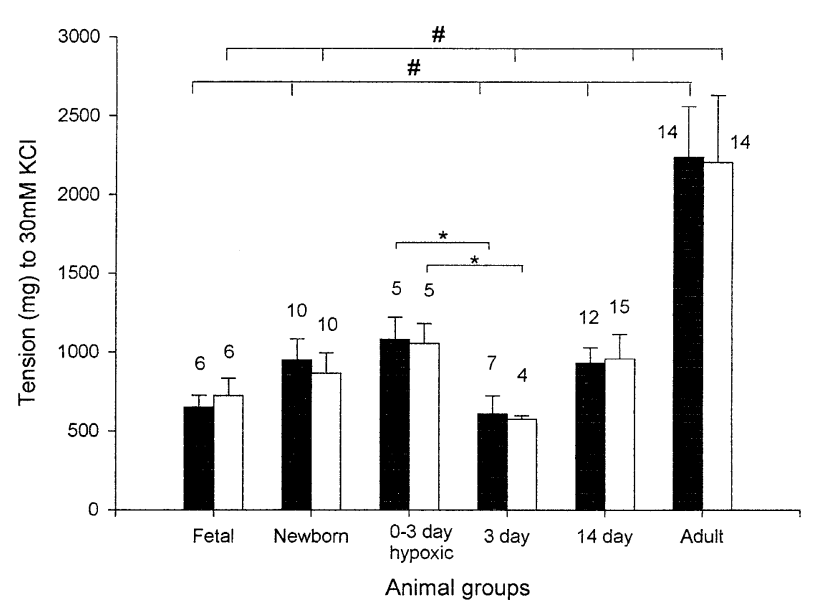

Figure 1 The response of isolated porcine intrapulmonary arteries to $30 \mathrm{~mm}$ potassium chloride, at different ages, in normal animals and in those exposed to hypoxia, with and without endothelium. Each column shows the mean \pm s.e.mean. The number of animals used is indicated above each column. Solid columns indicate arteries with endothelium and empty columns those without. $\# P<0.05$ ANOVA, $* P<0.05$ Student $t$-test

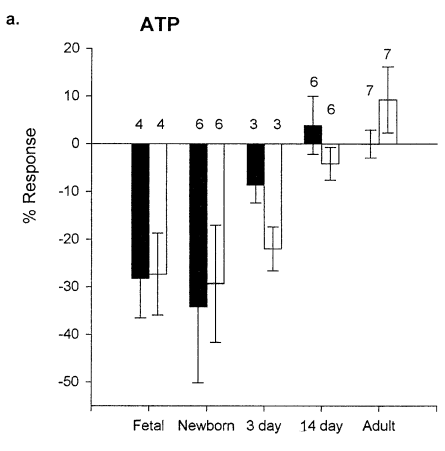

Age group

b.

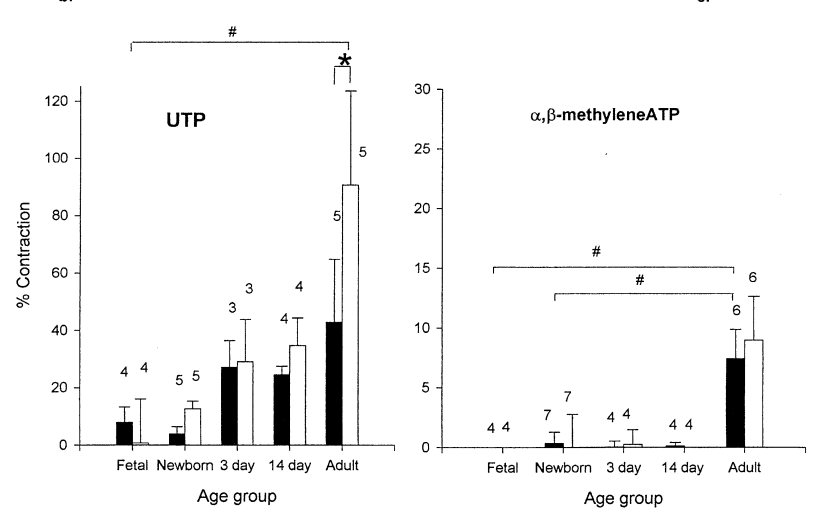

Figure 2 Histograms showing the mean response to (a) ATP, $20 \mathrm{~mm}$; (b) UTP, $20 \mathrm{~mm}$; (c) $\alpha, \beta$-meATP, $10 \mu \mathrm{M}$, at different ages. The data shown for each agonist gave the most significant (ANOVA) change in response with age and was derived from cumulative concentration-response curves. Columns show mean \pm s.e.mean. Solid columns indicate arteries with endothelium and empty columns those without. The number of animals used is indicated above each column. $\# P<0.05$ ANOVA, ${ }^{*} P<0.05$ Student $t$-test. a. ATP

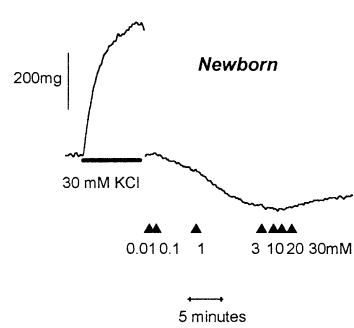

c. UTP

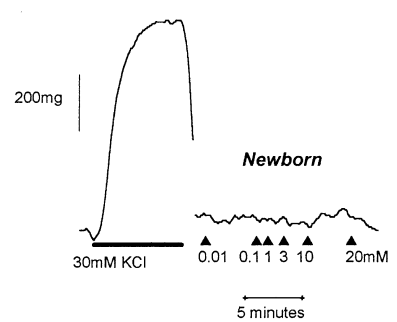

b. ATP

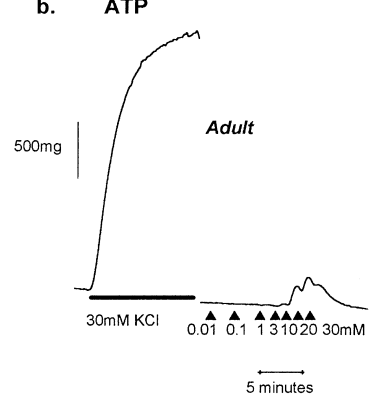

d. UTP

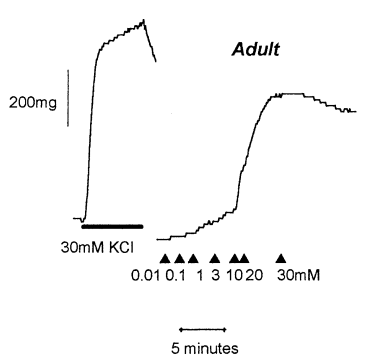

Figure 3 Representative traces for the responses of isolated porcine intrapulmonary arteries, with endothelium, to a bolus of $30 \mathrm{~mm} \mathrm{KCl}$ and cumulative doses of either ATP or UTP at resting tension. Responses are shown for $\operatorname{ATP}(\mathrm{a}, \mathrm{b})$ and $\operatorname{UTP}(\mathrm{c}, \mathrm{d})$ in newborn and adult vessels respectively. 


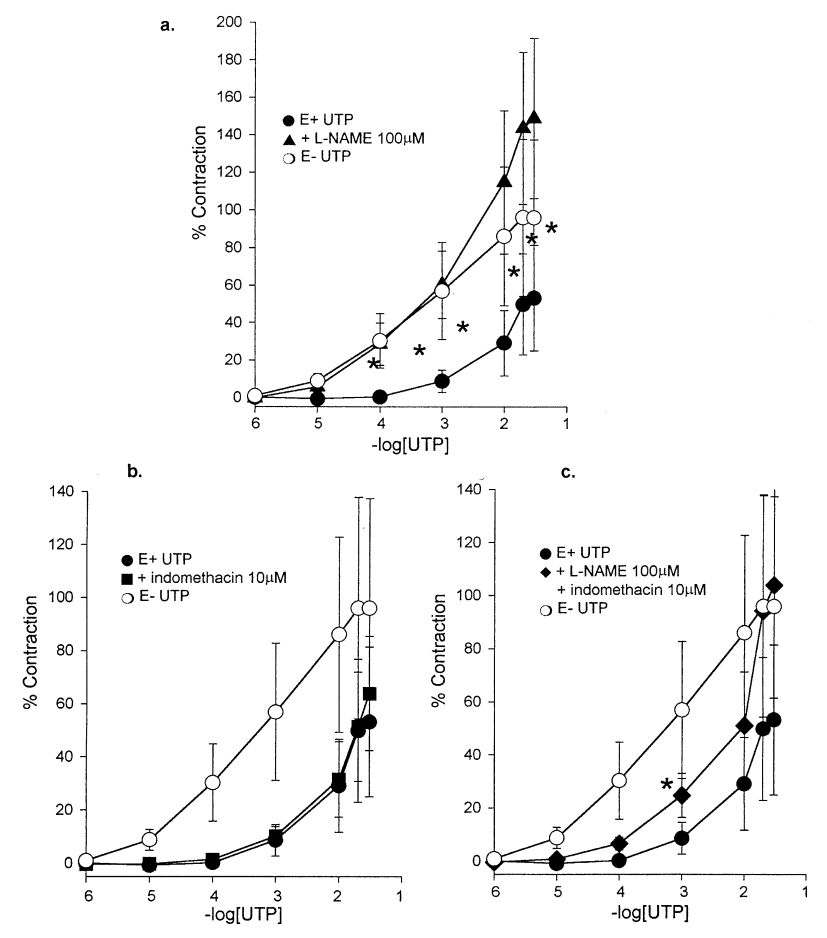

Figure 4 Porcine intrapulmonary arteries from four normal adults with and without endothelium exposed to UTP, and in vessels with endothelium following pre-incubation with (a) L-NAME $(100 \mu \mathrm{M})$, (b) indomethacin $(10 \mu \mathrm{M})$ or (c) L-NAME $(100 \mu \mathrm{M})$ and indomethacin $(10 \mu \mathrm{M})$, showing the mean response \pm s.e.mean. ${ }^{*} P<0.05$ between the treated vessels and the response of vessels with endothelium, Student $t$-test.

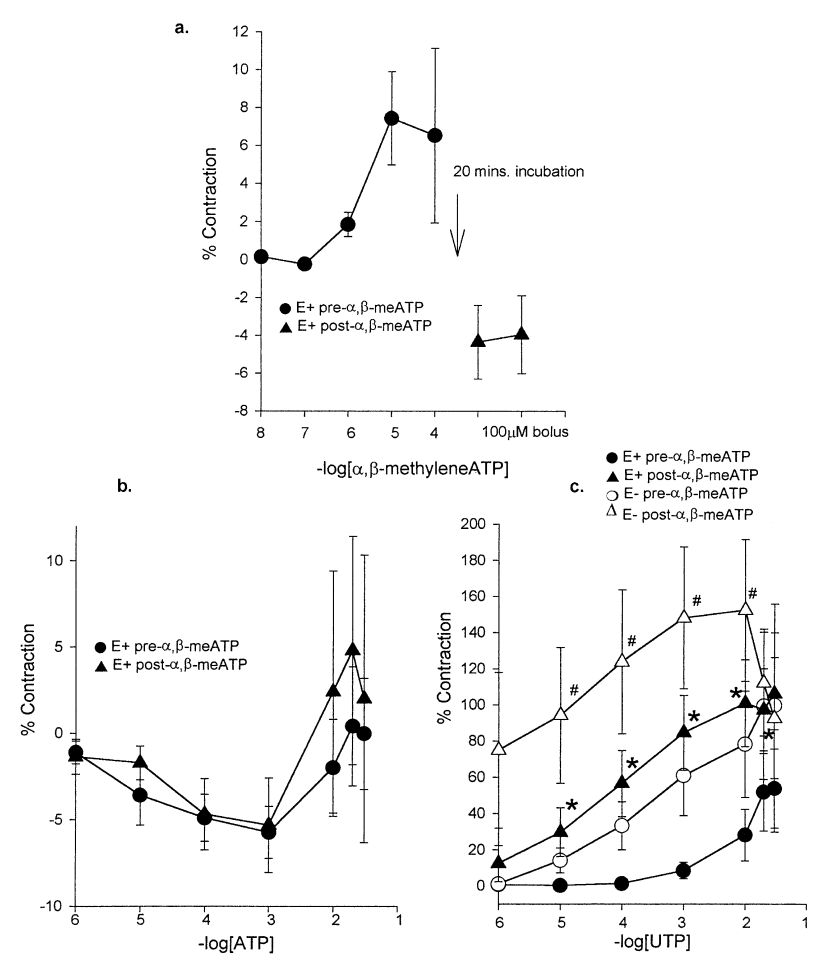

Figure 5 The effect of P2X-receptor desensitization by preincubation with $(100 \mu \mathrm{M}) \alpha, \beta$-meATP in isolated intrapulmonary arteries with endothelium from normal adult pigs. Effect on the response to (a) $\alpha, \beta$-meATP $(n=6)$; (b) ATP $(n=6)$; (c) UTP $(n=5)$, showing the mean response \pm s.e.mean. Empty symbols denote vessels without endothelium. ' $n$ ' indicates the number of animals used and applies to subsequent legends. * With and \# without endothelium, $P<0.05$ between treated and untreated vessels.
Effect of nitric oxide synthase and prostaglandin synthase inhibitors in adult porcine IPAs

The resting tone did not change significantly following incubation with either $100 \mathrm{mM}$ L-NAME (increased by $22 \pm 12 \%$ ) or $10 \mu \mathrm{M}$ indomethacin (decreased by $15 \pm 6 \%$ ) or with a combination of the two (increased by $4 \pm 7 \%$ ). The effect of the synthase inhibitors was assessed from the newly established baseline. The significant increase in UTP-induced contraction following removal of the endothelium from the normal adult pig IPA was mimicked by pre-incubation with LNAME $(100 \mu \mathrm{M})$ (Figure 4a). Pre-incubation with indomethacin $(10 \mu \mathrm{M})$ had no effect (Figure $4 \mathrm{~b})$, while a combination of the two inhibitors reduced the effect of L-NAME given alone (Figure 4c).

\section{$P 2 X$-receptor desensitization experiments}

In IPA from normal adult animals a 20 min pre-incubation with $100 \mu \mathrm{M} \alpha, \beta$-meATP, followed by a repeated dose of $100 \mu \mathrm{M} \alpha, \beta$-meATP desensitized the contractile response in vessels with or without endothelium (Figure $5 \mathrm{a}$ ). In adult vessels, the response to ATP was unchanged by pre-incubation

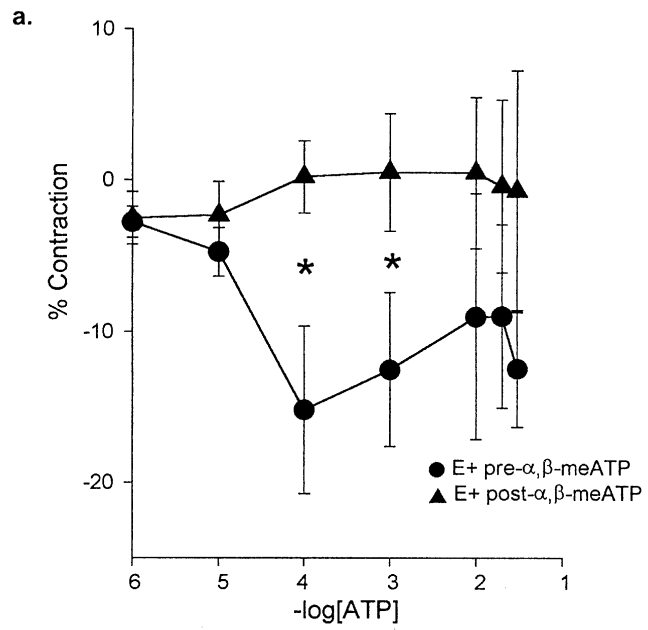

b.

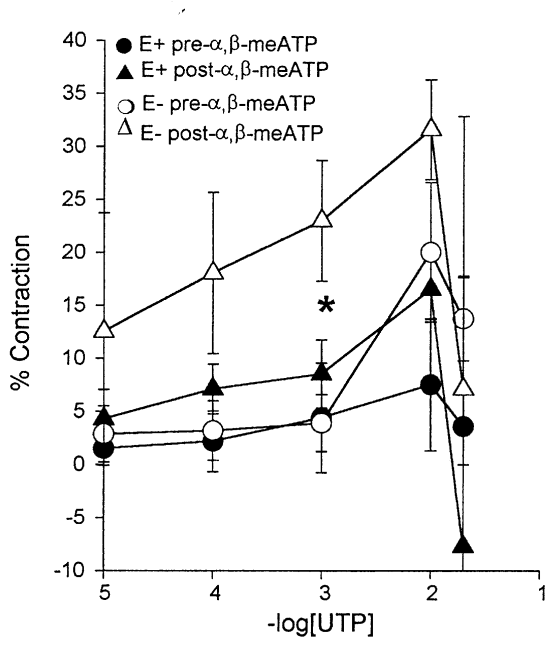

Figure 6 The effect of P2X-receptor desensitization by preincubation with $(100 \mu \mathrm{M}) \alpha, \beta$-meATP in isolated intrapulmonary arteries with endothelium from normal newborn pigs. Effect on the response to (a) ATP $(n=3)$; (b) UTP $(n=3)$ and (c) UTP $(n=3)$ without endothelium, showing the mean response \pm s.e.mean. $* P<0.05$. 
with $\alpha, \beta$-meATP (Figure 5b). UTP-induced contractions displayed a significantly augmented potency and magnitude in IPA with and without endothelium (Figure 5c).

In normal newborn piglets, the same protocol prevented the normal ATP-induced relaxation response $(P<0.05$ Figure $6 a)$. After pre-incubation with $\alpha, \beta$-meATP, UTP appeared to induce an increased contractile response but this was only statistically significant in vessels in which the endothelium had been removed (Figure 6b).

\section{Responses of intrapulmonary arteries from piglets with neonatal pulmonary hypertension}

The response to a bolus addition of $\mathrm{KCl}$ in IPA from animals exposed to chronic hypobaric hypoxia from birth for a period of 3 days was similar to the normal response at birth and greater than that in the normal at 3 days of age (Figure 1) $(P<0.05)$. Removal of the endothelium did not alter this observation.

The response to ATP and $\alpha, \beta$-meATP in IPAs from the hypoxic piglets was similar to that in normal age-matched healthy animals (Figure 7a,b). The contractile response to UTP was more similar to the normal response at birth than the normal at 3 days of age with (Figure 7c), or without (data not shown) endothelium.

\section{Discussion}

The present study has demonstrated that under resting conditions the contractile response of the porcine conduit intrapulmonary artery to P2-receptor agonists increased significantly between foetal and adult life. The contractile response was low in the perinatal animals suggesting that the

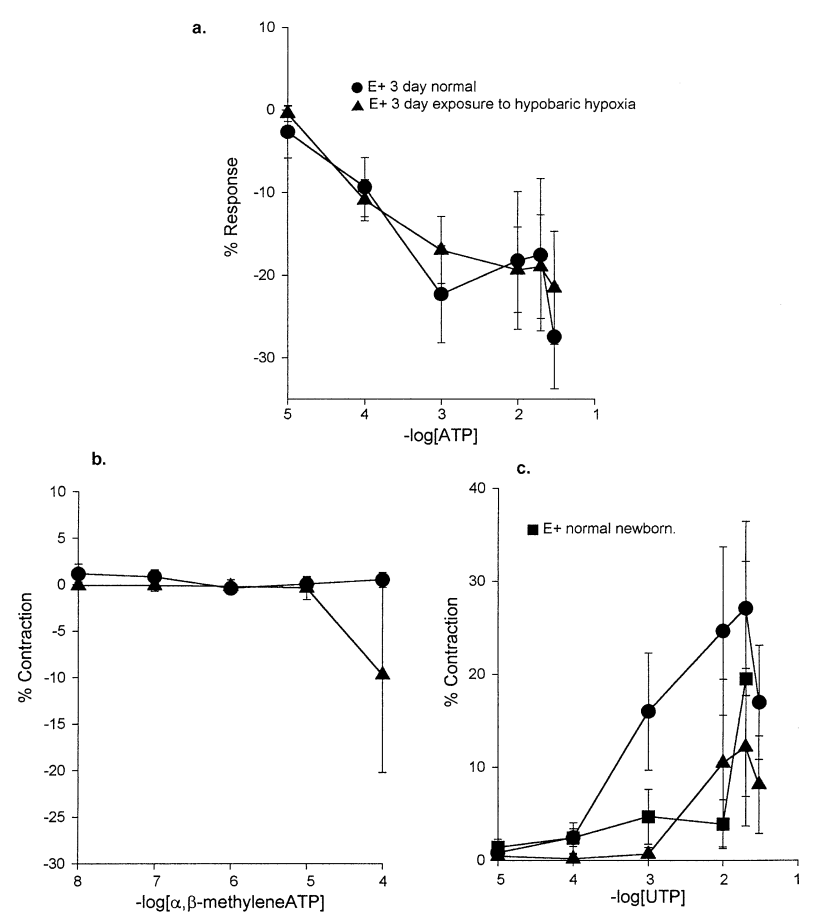

Figure 7 The effect of chronic pulmonary hypertension induced by hypoxia from birth for a period of 3 days on the response of isolated intrapulmonary arteries, with endothelium, to (a) ATP $(n=4)$; (b) $\alpha, \beta$-methyleneATP $(n=3) ; \quad$ (c) UTP $(n=3)$, showing the mean response \pm s.e.mean, normal newborn, normal 3 day-old both with endothelium. ${ }^{*} P<0.05$. agonists tested may not have physiological importance in the presence of the high pulmonary tone present at this age. A contractile response to UTP was evident in the normal foetal and newborn preparations, much earlier than ATP-induced contraction. UTP also had a greater contractile effect than either ATP or $\alpha, \beta$-meATP at all ages. The explanation for the increase in contractile response to the different nucleotides with age is unclear. The response to purines is generally tonedependent, vasoconstriction being favoured at low tone, such as is found in IPAs of mature normal animals. But the response to other contractile agonists also increases with age (Levy et al., 1995) and could be related to a progressive increase in smooth muscle cell contractile myofilament volume density (Hall \& Haworth, 1987).

$\alpha, \beta$-meATP only constricted adult porcine IPA and the responses were transient, and tachyphylactic, as described in the isolated IPAs of man and the adult rat (Liu et al., 1989a, b). Following reports of $\mathrm{P}_{2} \mathrm{X}_{1,2,4}$-receptor mRNA located on adult rat IPA smooth muscle it may be suggested that $\alpha, \beta$ meATP acts at the $\mathrm{P} 2 \mathrm{X}_{1}$-receptor subtype in the present study (Nori et al., 1998). It was interesting to note the absence of any contractile response in the IPAs of younger piglets, because the rat tail artery shows a greater P2X-receptor mediated vasoconstriction in the young rat than in the adult (Bao et al., 1989). In the adult porcine IPA, $\alpha, \beta$-meATP evoked a smaller contractile response at lower concentrations than either ATP or UTP. a, $\beta$-meATP has been shown to desensitize certain subtypes of $\mathrm{P} 2 \mathrm{X}$-contractile receptors ( $\mathrm{P} 2 \mathrm{X}_{1}$ and 3 ) (Burnstock, 1997). In the present study, $\alpha, \beta$-meATP reduced the relaxation response to low concentrations of ATP in the newborn pig IPA, and actually increased the contractile response to UTP. In the adult porcine IPA, the ATP- induced contractile responses were not blocked and the UTP-induced responses were increased by pre-incubation with $\alpha, \beta$-meATP. Other workers have also found the contractile response to ATP was not inhibited following P2X-receptor desensitization by $\alpha, \beta$-meATP in systemic vessels (Juul et al., 1993; Maguire et al., 1996; O'Connor et al., 1990) and potentiation of UTPinduced vasoconstriction has been reported in the isolated adult rat pelvic artery (Maguire et al., 1996). In addition, $\alpha, \beta$ meATP reduced ATP induced vasoconstriction of perfused adult rat lungs but it did not inhibit the UTP response (Rubino \& Burnstock, 1996). $\alpha, \beta$-meATP has been shown to be an inhibitor of ectoATPase activity on bovine aortic endothelial cells (Chen \& Lin, 1997). EctoATPase inhibition may increase the levels of ATP and UTP and therefore increase the contractile response at low tone (Zimmerman, 1996).

UTP evoked a marked vasoconstriction of IPA at all ages in the present study. The role of UTP in the cardiovascular system, normal or abnormal, is uncertain. High concentrations are present in platelets and UTP can be released from the endothelium under conditions of increased shear stress and hypoxia (Saiag et al., 1995), suggesting the involvement of UTP in high flow and hypoxia-induced vasoconstriction in vivo. Ours is the first study to demonstrate a vasoconstrictor action for UTP which was greater than that of purines, as it was throughout life in porcine IPA. The observation that UTP induces a greater contractile response in the adult porcine IPA without endothelium would suggest UTP-stimulated release of an EDRF (Purkiss et al., 1994). This was confirmed in the present study with L-NAME. A pyrimidine-preferring P2Y receptor (G-protein coupled receptor superfamily) is thought to mediate the contractile response of the adult rabbit coronary artery induced by UDP and UTP (Matsumoto et al., 1997). In the present study UTP evoked an $\alpha, \beta$-meATPinsensitive vasoconstriction, suggesting action at a $\mathrm{P}_{2} \mathrm{Y}_{2^{-}}$ 
receptor, recently identified in adult rat small pulmonary artery (Hartley et al., 1998). However, the observation that ATP seemed to act as a partial agonist also evoking an $\alpha, \beta$ meATP-insensitive vasoconstriction would lead us to conclude that the responses to both UTP and ATP were mediated by a $\mathrm{P} 2 \mathrm{Y}_{4}$-receptor. This conclusion is based on receptor expression studies by Nicholas et al. (1996), demonstrating that UTP was more potent than ATP at the $\mathrm{P}_{2} \mathrm{Y}_{4}$-receptor, while both nucleotides were equipotent at the $\mathrm{P} 2 \mathrm{Y}_{2}$ and that the $\mathrm{P} 2 \mathrm{Y}_{6}$ was only potently activated by UDP.

Chronic hypoxia produces vascular remodelling of the intrapulmonary arteries in the newborn piglet and other species including man, which involves an increase in smooth muscle (Allen \& Haworth, 1986; Haworth, 1993). However, in both present and previous studies on chronically hypoxic piglets, the increase in smooth muscle was not associated with an increase in the contractile response to potassium chloride (Tulloh et al., 1997). Hypoxic exposure prevented the normal postnatal reduction in response from taking place. The responses evoked by $\mathrm{P} 2$-receptor agonists were also similar to those of vessels from normal piglets at birth, prior to entering the hypobaric chamber. Reports from our own group and others make it clear that the vasoconstrictor response to other agonists is not always enhanced following exposure to chronic

\section{References}

ALLEN, K. \& HAWORTH, S.G. (1988). Human postnatal pulmonary arterial remodelling: ultrastructural studies of smooth muscle cell and connective tissue maturation. Lab. Invest., 59, 702-709.

ALLEN, K.M. \& HAWORTH, S.G. (1986). Impaired adaptation of pulmonary circulation to extrauterine life in newborn pigs exposed to hypoxia: an ultrastructural study. J. Pathol., 150, $205-212$.

BAO, J.X., ERIKSSON, I.E. \& STJARNE, L. (1989). Age-related variations in the relative importance of noradrenaline and ATP as mediators of the contractile response of rat tail artery to sympthetic nerve stimulation. Acta Physiol. Scand., 136, $287-$ 288.

BENHAM, C.D. \& TSIEN, R.W. (1987). A novel receptor-operated $\mathrm{Ca} 2+$ permeable channel activated by ATP in smooth muscle. Nature, 328, $275-278$.

BURNSTOCK, G. (1997). The past, present and future of purine nucleotides as signalling molecules. Neuropharmacology, 36, $1127-1139$.

CHEN, B.C. \& LIN, W. (1997). Inhibition of ecto-ATPase by the $\mathrm{P}_{2}$ purinoceptor agonists, ATP $\gamma \mathrm{S}, \alpha, \beta$-meATP, and AMP-PNP, in endothelial cells. Biochem. Physical Res. Commun., 233, $442-$ 446.

GOETZ, U., DA-PRADA, M. \& PLETSCHER, A. (1971). Adenine-, guanine- and uridine-5'-phosphonucleotides in blood platelets and storage organelles of various species. J. Pharmacol. Exp. Ther., 178, 210-215.

HALL, S.M. \& HAWORTH, S.G. (1987). Conducting pulmonary arteries: structural adaptation to extrauterine life. Cardiovascular Res., 21, 208-216.

HARPER, S., WEBB, T.E., CHARLTON, S.J., NG, L.L. \& BOARDER, M.R. (1998). Evidence that $P_{2} \quad Y_{4}$ nucleotide receptors are involved in the regulation of rat aortic smooth muscle cells by UTP and ATP. Br. J. Pharmacol., 124, 703-710.

HARTLEY, S.A., KATO, K., SALTER, K.J. \& KOZLOWSKI, R.Z. (1998). Functional evidence for a novel suramin-insensitive pyrimidine receptor in rat small pulmonary arteries. Circ. Res., 83, 940-946.

HAWORTH, S.G. (1979). Pulmonary vascular structure in persistent fetal circulation In: Godman, M.J. \& Marquis, R.M. (eds). Paediatric Cardiology. Heart Disease in the Newborn, Churchill Livingstone: Edinburgh, pp $67-78$.

HAWORTH, S.G., HALL, S.M., CHEW, M. \& ALLEN, K. (1987). Thinning of fetal pulmonary arterial wall and postnatal remodelling: ultrastructural studies on the respiratory unit arteries of the pig. Virchows Arch A, 411, 161-171. hypoxia (Tulloh et al., 1997; Porcelli \& Bergman, 1983; Karamsetty et al., 1995; Maclean et al., 1996).

Chronic hypobaric hypoxia may have remodelled the IPA in such a way as to produce a 'pre-contracted, high tone vessel' which would favour a relaxation response, judging by the tonedependent nature of the responses evoked by P2-agonists. An alternative explanation would be that the smooth muscle sensitivity to ATP induced relaxation was up-regulated to balance the vasoconstricting effect of hypoxia in vivo. An initial up-regulation of IPA vasodilatation to EDRF and activation of $\mathrm{K}^{+}{ }_{\text {-ATP }}$ channels has been shown in response to acute hypoxia, prior to a secondary loss of vasodilatation (Wadsworth, 1994).

The present study suggests that the $\mathrm{P} 2 \mathrm{X}_{1}$-receptor mediates the $\alpha, \beta$-meATP vasoconstriction response in the adult. However, UTP was found to be a more potent vasoconstrictor than ATP at all ages, suggesting the $\alpha, \beta$-meATP-insensitive contractile responses were mediated by the $\mathrm{P}_{2} \mathrm{Y}_{4}$-receptor subtype. Neonatal pulmonary hypertension induced by chronic hypoxia did not affect these conclusions.

We thank Dr P.J. Boels for his pharmacological and statistical advice. This work was funded by the British Heart Foundation.
HAWORTH, S.G. (1993). Persistent Fetal Circulation: Principles of Diagnosis and Management. In: Hanson, M.A., Spender, J.A.D. \& Rodeck, C.H. (ed) Fetus and Neonate, Cambridge Press: Cambridge, pp 396-423.

JUUL, B., PLESNER, L. \& AALKJAER, C. (1993). Effects of ATP and related nucleotides on the tone of the isolated rat mesenteric resistance arteries. J. Pharmacol. Exp. Ther., 264, 1234-1240.

KARAMSETTY, V.S.N.M.R., KANE, K.A. \& WADSWORTH, R.M. (1995). The effects of chronic hypoxia on the pharmacological responsiveness of the pulmonary artery. Pharmac. Ther., 68, $233-246$.

KASAKOV, L. \& BURNSTOCK, G. (1983). The use of the slowly degradable analogue $\alpha, \beta$-methylene ATP, to produce desensitisation of the $\mathrm{P}_{2}$-purinoceptor: effect on non-adrenergic noncholinergic responses of the guinea-pig urinary bladder. Eur. J. Pharmacol., 86, $291-294$.

KENNEDY, C. \& LEFF, P. (1995). How should P2-purinoceptors be classified pharmacologically. TIPS, 16, 168-173.

LeVY, M., TUlloh, R.M., KOMAI, H., STUART-SMITH, K. \& HAWORTH, S.G. (1995). Maturation of the contractile response and its endothelial modulation in newborn porcine intrapulmonary arteries. Pediatr. Res., 38, 25-29.

LIU, S.F., HISLOP, A.A., HAWORTH, S.G. \& BARNES, P.J. (1992) Developmental changes in endothelium-dependent pulmonary vasodilatation in pigs. Br. J. Pharmacol., 106, 324-330.

LIU, S.F., MCCORMACK, D.G., EVANS, T.W. \& BARNES, P.J. (1989a). Characterization and distribution of P2-purinoceptor subtypes in rat pulmonary vessels. J. Pet, 251, 1204-1210.

LIU, S.F., MCCORMACK, D.G., EVANS, T.W. \& BARNES, P.J. (1989b). Evidence for two P2-purinoceptor subtypes in human small pulmonary arteries. Br. J. Pharmacol., 98, 1014-1020.

MACLEAN, M.R., SWEENEY, G., BAIRD, M., MCCULLOCH, K.M., HOUSLAY, M. \& MORECROFT, I. (1996). 5-Hydroxytryptamine receptors mediating vasoconstriction in pulmonary arteries from control and pulmonary hypertensive rats. Br. J. Phrmacol., 119, 917-930.

MAGUIRE, M.H., DOBRONYI, I., HUNG, K.S. \& SATCHELL, D.G. (1996). Do different receptors mediate ATP- and UTP-elicited contraction of rat pelvic artery? Drug Develop Res., 37, 165.

MATSUMOTO, T., NAKANE, T. \& CHIBA, S. (1997). UTP induces responses in the isolated and perfused canine epicardial coronary artery via UTP-preferring P2Y receptors. Br. J. Pharmacol., 122, $1625-1632$. 
MCCORMACK, D.G., BARNES, P.J. \& EVANS, T.W. (1989). Purinoceptors in the pulmonary circulation of the rat and their role in hypoxic vasoconstriction. Br. J. Pharmacol., 98, 367-372.

NEELY, C.F., HAILE, D.M., CAHILL, B.E. \& KADOWITZ, P.J. (1991). Adenosine and ATP produce vasoconstriction in the feline pulmonary vascular bed by different mechanisms. J. Pet, 258, $753-761$.

NEELY, C.F., MATOT, I., BATRA, V.K., BO, X. \& BURNSTOCK, G. (1996). P2X purinoceptors in the feline pulmonary vascular bed: distribution and selective in vivo pharmacological probes. Am. J. Physiol., 270, L889 - L897.

NICHOLAS, R.A., LAZAROWSKI, E.R., WATT, W.C., LI, Q., BOYER, J. \& HARDEN, T.K. (1996). Pharmacological and second messenger signalling selectives of cloned $\mathrm{P}_{2} \mathrm{Y}$ receptors. J. Auto. Pharmacol., 16, $319-323$.

NORIS, S., FUMAGALLI, L., BO, X., BOGDANOV, Y. \& BURNSTOCK, G. (1998). Coexpression of mRNAs for $\mathrm{P} 2 \mathrm{X}_{1}, \mathrm{P} 2 \mathrm{X}_{2}$ and $\mathrm{P} 2 \mathrm{X}_{4}$ receptors in rat vascular smooth muscle: an in situ hybridisation and RT-PCR study. J. Vasc. Res., 35, 179-185.

O'CONNOR, S.E., WOOD, B.E. \& LEFF, P. (1990). Characterization of $\mathrm{P} 2 \mathrm{x}$-receptors in rabbit isolated ear artery. Br. J. Pharmacol., 101, $640-644$.

PORCELLI, R.J. \& BERGMAN, M.J. (1983). Effects of chronic hypoxia on pulmonary vascular responses to biogenic amines. J. Appl. Physiol., 55, 534-540.

PURKISS, J.R., WILKINSON, G.F. \& BOARDER, M.R. (1994). Differential regulation of inositol 1,4,5-triphosphate by coexisting P2Y-purinoceptors and nucleotide receptors on bovine aortic endothelial cells. Br. J. Pharmacol., 111, $723-728$.

RALEVIC, V. \& BURNSTOCK, G. (1991). Effects of purines and pyrimidines on the rat mesenteric arterial bed. Br. J. Pharmacol., 69, $1583-1590$.
RALEVIC, V. \& BURNSTOCK, G. (1998). Receptors for purines and pyrimidines. Pharmacol. Rev., 50, 413-492.

RUBINO, A. \& BURNSTOCK, G. (1996). Evidence for a $\mathrm{P}_{2}$ purinoceptor mediating vasoconstriction by UTP, ATP and related nucleotides in the isolated pulmonary vascular bed of the rat. Br. J. Pharmacol., 118, $1415-1420$.

SAIAG, B., BODIN, P., SHACOORI, V., CATHERINE, M., RAULT, B. \& BURNSTOCK, G. (1995). Uptake and flow-induced release of uridine nucleotides from isolated vascular endothelial cells. Endothelium, 2, 279-285.

SAIAG, B., MILON, D., ALLAIN, H., RAULT, B. \& DRIESSCHE, J.V.D. (1990). Constriction of the smooth muscle of rat tail and femoral arteries and dog saphenous vein is induced by uridine triphosphate via a 'pyrimidinoceptors' and by adenosine triphosphate via P2X-purinoceptors. Blood Vessels, 27, 352-364.

SAIAG, B., MILON, D., GUELOU, M.C., VAN DEN DRIESSCHE, J. \& RAULT, B. (1987). Heterogeneity of purinergic $P 2$ receptors at the level of the caudal artery of the rat and the saphenous vein of the dog. C R Seances Soc. Biol. Fil., 181, 168-177.

TUlLOH, R.M.R., HISLOP, A.A., BOELS, P.J., DEUTSCH, J. \& HAWORTH, S.G. (1997). Chronic hypoxia inhibits postnatal maturation of porcine intrapulmonary artery relaxation. Am. J. Physiol., 272, H2436- H2445.

VON KUGELGENI, T. \& STARKE, K. (1990). Evidence for two separate vasoconstriction-mediating nucleotide receptors, both distinct from the P2X-receptor, in rabbit basilar artery: a receptor for pyrimidine nucleotides and a receptor for purine nucleotides. Arch. Pharmacol., 341, 538-546.

WADSWORTH, R.M. (1994). Vasoconstrictor and vasodilator effects of hypoxia. Trends Pharmacol Sci, 15, 47-53.

ZIMMERMAN, H. (1996). Extracellular purine metabolism. Drug Metab. Res., 39, 337-352.

(Received January 13, 1999 Revised June 10, 1999 Accepted July 6, 1999) 